\title{
Correction to: Bibliometric analysis of global research on air pollution and human health: 1998-2017
}

\section{Sushma Dhital ${ }^{1} \cdot$ Dipesh Rupakheti $^{2}$}

Published online: 25 June 2019

(C) Springer-Verlag GmbH Germany, part of Springer Nature 2019

Correction to: Environmental Science and Pollution Research (2019) 26:13103-13114 https://doi.org/10.1007/s11356-019-04482-x

The original publication of this paper contain typographical mistakes.

'Michael Bell' mentioned in this paper should be corrected as 'Michelle L. Bell'.

Publisher's note Springer Nature remains neutral with regard to jurisdictional claims in published maps and institutional affiliations.

The online version of the original article can be found at https://doi.org/ 10.1007/s11356-019-04482-x

Sushma Dhital susd834@gmail.com

1 School of Public Health, Lanzhou University, No. 222 South Tianshui Road, Lanzhou 730000, China

2 State Key Laboratory of Cryospheric Science, Northwest Institute of Eco-Environment and Resources, Chinese Academy of Sciences, Lanzhou 730000, China 